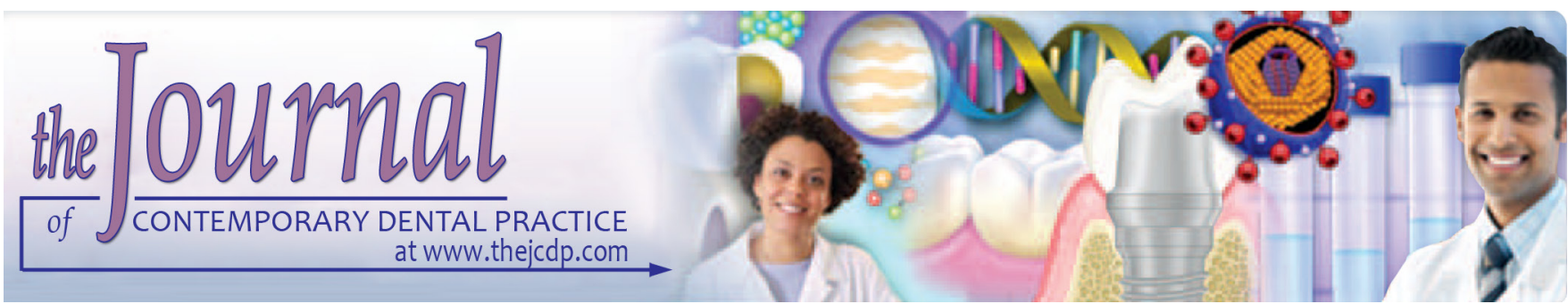

\title{
Assessment of Knowledge about Dental Ergonomics among Dental Students of King Saud University, Riyadh, Kingdom of Saudi Arabia
}

\author{
${ }^{1}$ Naif A Almosa, ${ }^{2,3}$ Hamayun Zafar
}

\begin{abstract}
Aim: To assess the knowledge about dental ergonomics and work-related musculoskeletal disorders (WRMSDs) among dental students of King Saud University (KSU), Riyadh, Kingdom of Saudi Arabia, undergoing practical clinical training.

Materials and methods: A self-designed questionnaire after pre-testing was distributed to 150 dental students of KSU undergoing clinical training, to collect data related to (a) basic knowledge about dental ergonomics; (b) any course/workshop about dental ergonomics attended; (c) basic knowledge about WRMSDs; (d) familiarity about preventive measures to decrease the risk of WRMSDs; and (e) knowledge about treatment options for WRMSDs.
\end{abstract}

Results: One hundred forty-two students (95\%) returned the completed questionnaires, of them 54 (38\%) were males and $88(62 \%)$ were females. The main findings of the study are that only $30 \%$ of the students knew about dental ergonomics; $93 \%$ of students have not attended any course/workshop about dental ergonomics; about half the students knew about WRMSDs; $62 \%$ of the students did not know about preventive measures to decrease the risk of WRMSDs, and $80 \%$ of students did not have knowledge about treatment options for WRMSDs. In general, female students had a better understanding of dental ergonomics and WRMSDs than male students.

Conclusion: The basic knowledge of the dental ergonomics among dental students at King Saud University, Riyadh, Kingdom of Saudi Arabia is not adequate.

${ }^{1}$ Department of Pediatric Dentistry and Orthodontics, College of Dentistry, King Saud University, Riyadh, Kingdom of Saudi Arabia

${ }^{2}$ Department of Rehabilitation Sciences, College of Applied Medical Sciences, and, Rehabilitation Research Chair, King Saud University, Riyadh, Kingdom of Saudi Arabia

${ }^{3}$ Department of Odontology, Clinical Oral Physiology, Faculty of Medicine, Umea University, Sweden.

Correspondind Author: Naif A Almosa, Department of Pediatric Dentistry and Orthodontics, College of Dentistry, King Saud University, Riyadh, Kingdom of Saudi Arabia, e-mail: nalmosa@ksu.edu.sa
Clinical significance: There is a need for introducing dedicated theoretical and practical courses covering all aspects of dental ergonomics in the undergraduate curriculum of dental education.

Keywords: Dental students, Ergonomics, Musculoskeletal disorders, Kingdom of Saudi Arabia.

How to cite this article: Almosa NA, Zafar H, Assessment of Knowledge about Dental Ergonomics among Dental Students of King Saud University, Riyadh, Kingdom of Saudi Arabia. J Contemp Dent Pract 2019;20(3):324-329.

Ethical statement: The study protocol was approved by the Research and Ethics Committee at the College of Dentistry, King Saud University (E-18-3166).

Source of support: Nil

Conflict of interest: None

\section{INTRODUCTION}

The very nature of clinical work by dentists requires exceedingly precise and repeated wrist and hand movements to perform the required tasks in the confined working area of the patient's mouth. ${ }^{1}$ The required stability of hands position of the dentists to dispense dental treatment is usually achieved at the expense of prolonged sitting in static, uncomfortable and awkward postures causing musculoskeletal loading, particularly in the lumbar region. In addition, the dentists also maintain different inconvenient neck positions and keep shoulders in flexed and abducted postures for long durations, requiring sustained static isometric muscle contractions. ${ }^{2}$

Prolonged inconvenient static work postures requiring high static isometric muscle activity has been suggested as risk factors for developing WRMDs among dentists. ${ }^{3}$ A recent review has reported that $54-93 \%$ of dental professionals sustain WRMDs, ${ }^{4}$ with the involvement of the neck, shoulders, upper extremities, and lower back. ${ }^{5-7}$ It is also reported that WRMDs is the leading cause of early retirement among dentists. ${ }^{8}$ 
The use of 'ergonomics' is advocated to minimize WRMDs among dentists. ${ }^{9}$ Ergonomics is the scientific discipline that deals with the interactions between the worker and the working environment. Hence, the principles of ergonomics are used to minimize physical, visual and psychological strain on the body while interacting with the working environment. This is mainly achieved in two ways, adopting least straining static postures and movement patterns by the worker while performing the duties, and by using properly designed products and procedures for maximum efficiency, safety and comfort of the worker.

Application of dental ergonomics can include a number of different factors such as adjustment of dentist's and the patient's chairs, placing instruments in easy reach, and maintaining optimal postures for different clinical procedures to minimize the physical strain on the neuro-musculoskeletal systems of the dentists. Thus, the dentists need proper knowledge about the principles of dental ergonomics to apply them in their clinical practice to protect themselves from WRMD. Ideally, this information should be available to the dentists from the very beginning of clinical training as dental students. ${ }^{10}$ In general, the 'dental ergonomics' is not a standalone subject taught to the dental students, therefore the present study was undertaken with the objective to assess the knowledge of dental ergonomics and WRMSDs among dental students who were undergoing practical clinical training.

\section{MATERIALS AND METHODS}

A questionnaire-based cross-sectional survey was conducted in 2017 among undergraduate dental students of both genders in the College of Dentistry, King Saud University, Riyadh, Kingdom of Saudi Arabia. A selfdesigned questionnaire was used for the collection of information. A questionnaire was distributed along with instructions and purpose of survey to 150 dental students who had started to work with patients in the dental chair or with manikins. Informed consent to participate in this study was obtained from all students. Ethical approval was obtained from the Institutional Review Board No. E-18-3166.

The data include age, gender and academic year of each participant. The questionnaire contained five questions printed on a single page to be filled by each participant by hand. Before the data collection, the validation of the questionnaire was established by means of face validation involving two other experts of questionnaire-based surveys. The reliability was assessed by distributing 10 questionnaires randomly among 10 students. They were asked again to answer the questionnaire after an interval of 2 weeks. The similarity percent of answers of the testretest questionnaire was $95 \%$. The only variation was in words chosen to describe in the second part of the first 2 questions, see below.

All questions were of a dichotomic nature (Yes/No). Only for the first 2 questions, in case of "yes" reply, the participant was required to briefly explain further in his/ her own words. The questionnaire was comprised of the following questions:

- Question 1. Do you know about dental ergonomics? Yes $\square$ No $\square$

- If your reply is yes, briefly explain what is your understanding of 'dental ergonomics'.

- Question 2: Have you ever attended a course/workshop or online lecture etc. about dental ergonomics? Yes $\square$ No

- If your reply is yes, briefly explain about the course/ workshop or online lecture etc., you attended

- Question 3. Do you know about work-related musculoskeletal disorders?

- Question 4. Are you familiar with preventive techniques to decrease the possible risk of having work-related musculoskeletal disorders?

- Question 5. Are you familiar with remedies/treatment options once you are subjected to work-related musculoskeletal disorders?

- Descriptive statistics were used to summarize the data.

\section{RESULTS}

The total of 142 students ( 54 males, mean age 24 years SD 2.1; 88 females, mean age 23 years SD 0.6) returned the hand filled completed questionnaires. Graphs 1 and 2 show the results of knowledge about dental ergonomics and WRMSDs among all the participants and based on genders, respectively. Generally, the response to question no. 1 about the knowledge of dental ergonomics, 99 out of 142 participants $(70 \%)$ replied 'no', while 43 participants $(30 \%)$ replied 'yes'. With regard to the gender, 45 out of 54 males $(83 \%)$ and 54 out of $88(61 \%)$ females did not know about the dental ergonomics, whereas, only 9 participants out of 54 males (17\%) and 34 participants out of $88(39 \%)$ females knew about the dental ergonomics. In addition, the second part of the question no. 1 where the participants were asked to describe their understanding of the dental ergonomics in case the answer was 'yes', 31 (7 males, 24 females) out of 43 (72\%) were able to reply correctly, and 12 ( 2 males, 10 females) out of $43(28 \%)$ were unable to reply correctly.

In response to question no. 2 related to attending any course/workshop or online lecture on the dental ergonomics, 132 (50 males and 82 females) out of 142, 


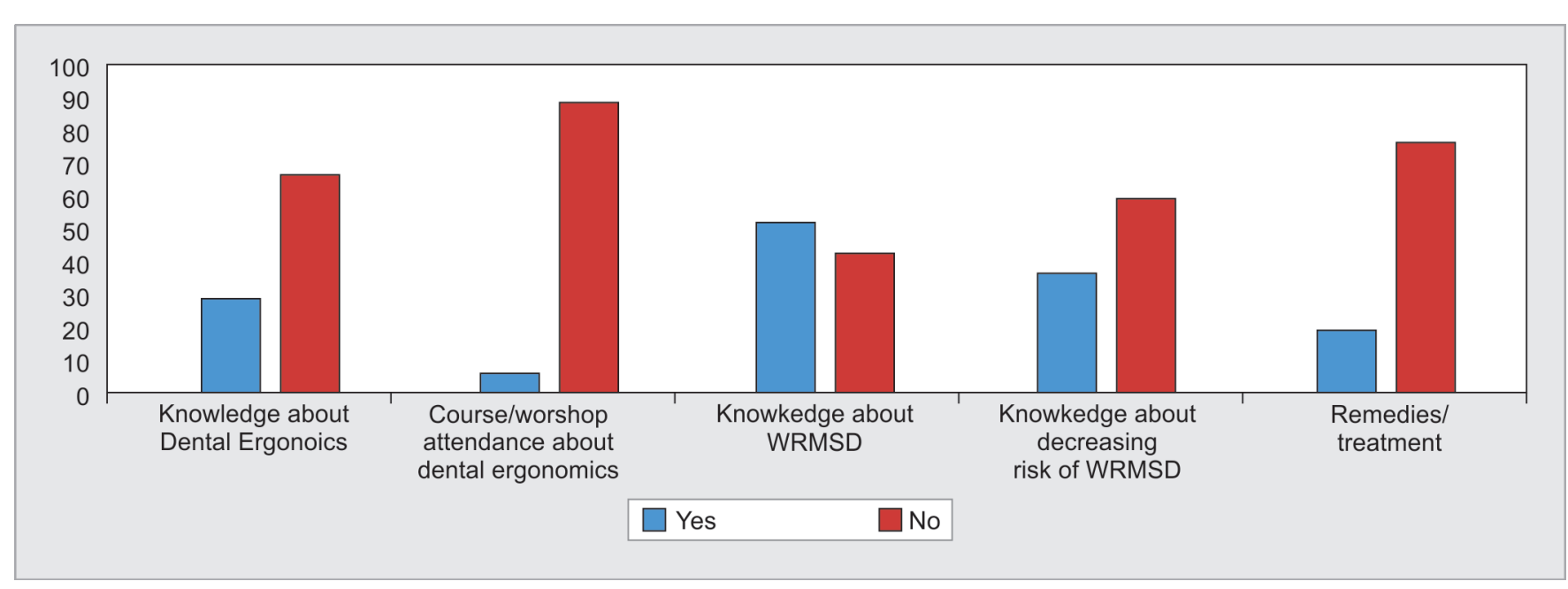

WRMSD: Work-related musculoskeletal disorders

Graph 1: Knowledge about dental ergonomics among dental students (\%)

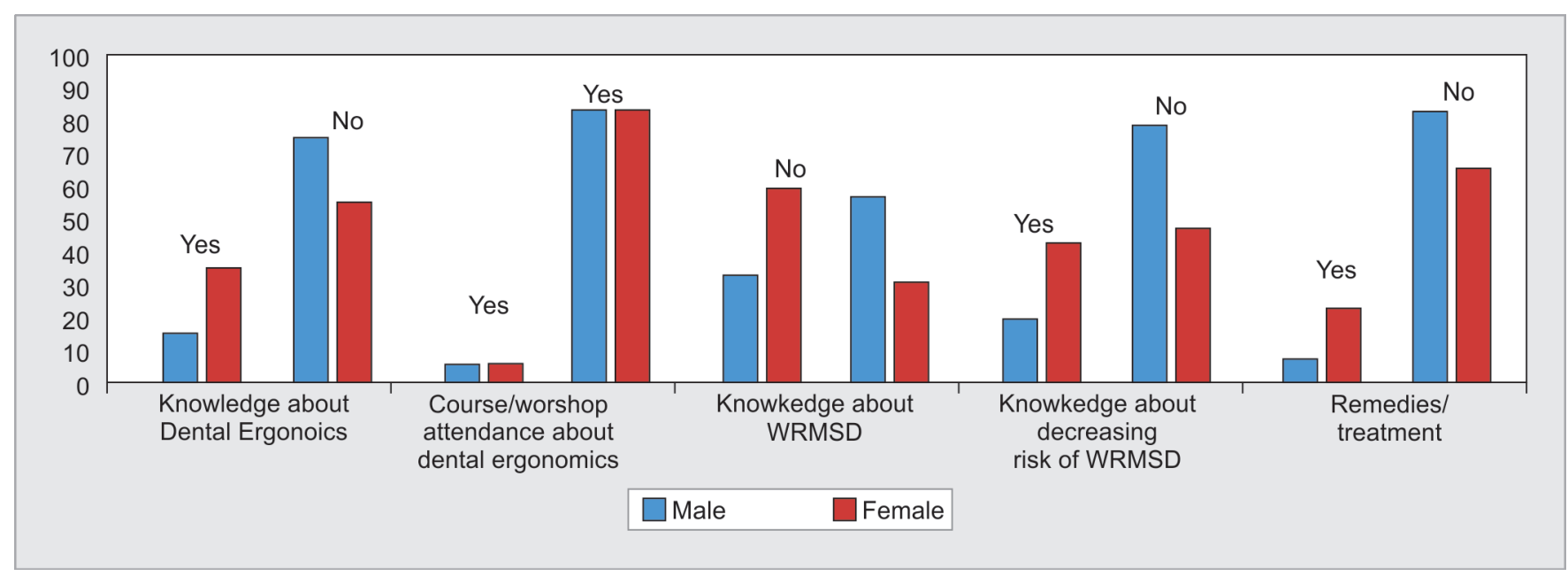

WRMSD: Work-related musculoskeletal disorders

Graph 2: Gender-based knowledge about dental ergonomics among dental students (\%)

which represent $93 \%$ of the included participants, replied 'no', while only 10 (4 males and 6 females), which represent $7 \%$ of the included participants, replied 'yes'. With regard to the gender, $7 \%$ of males (4 out of 54 ) and $7 \%$ of females (6 out of 88 ) had previously attended any course/ workshop or online lecture on the dental ergonomics. Moreover, the second part of the question no. 2 where the participants were asked to describe their source of knowledge about dental ergonomics in case the answer was 'yes', only 4 participants ( 2 males and 2 females) out of $10(40 \%)$ have provided the information. The 2 males and 1 female have seen online lectures and 1 female has attended a demonstration by dental chair manufacture during a dental conference.

In response to question no. 3 regarding knowledge about the work-related musculoskeletal disorders, 64 (34 males and 30 females) out of total 142, which represent $45 \%$ of included participants, have replied with 'no', and 78 (20 males and 58 females), which represent 55\% of included participants, have replied with 'yes'. With regard to the gender, $63 \%$ of males (34 out of 54 ) and $34 \%$ of females (30 out of 88 ) had no knowledge about the work-related musculoskeletal disorders, while, 37\% of males ( 20 out of 54 ) and $66 \%$ of females (58 out of 88 ) knew about the work-related musculoskeletal disorders

In response to question 4 regarding the knowledge about preventing the work-related musculoskeletal disorders, 88 (42 males and 46 females) out of total 142, which represent $62 \%$ of included participants, have replied with 'no', and 54 (12 males and 42 females), which represent $38 \%$ of included participants, have replied with 'yes'. In the aspect of gender, $78 \%$ of males ( 42 out of 54 ) and $52 \%$ of females (46 out of 88) had no knowledge about the work-related musculoskeletal disorders, while, $8 \%$ males (12 out of 54 ) and $78 \%$ females (42 out of 88 ) knew about the prevention of work-related musculoskeletal disorders.

In response to question 5 related to the knowledge about the remedies for the work-related musculoskeletal disorders, 114 (49 males and 65 females) out of total 142, which represent $80 \%$ of included participants, have 
replied with 'no', and 28 (5 males and 23 females), which represent $20 \%$ of included participants, have replied with 'yes'. In the aspect of gender, $84 \%$ of males (49 out of 54 ) and $74 \%$ of females (65 out of 88 ) had no knowledge about the remedies for the work-related musculoskeletal disorders, while, $7 \%$ males ( 5 out of 54 ) and $26 \%$ females (23 out of 88 ) knew about the remedies for the workrelated musculoskeletal disorders.

\section{DISCUSSION}

The findings of this study reveal that the dental students of the most prestigious dental college in Kingdom of Saudi Arabia who have already started to practice dental procedures have a little knowledge about dental ergonomics. The data of the present study shows that $70 \%$ of the participants replied negatively when they were asked if they know about dental ergonomics. For all other questions related to attending a lecture or course about dental ergonomics, prevention, and treatment of WRMSDs, the majority of the participants replied negatively, while $55 \%$ of the participants replied positively when the question was related to the knowledge about WRMSDs.

Lack of knowledge about dental ergonomics among dental students seems to be a universal issue, as many studies from different parts of the world have shown similar results. For example, Cervera-Espert et al. found only $29 \%$ of the dental students of Valencia University, Spain, were correctly positioning themselves in the dentist chair. ${ }^{11}$ Movahhed et al. have reported that $66 \%$ of dental students of Mashhad University, Iran, were at intermediate and high-risk levels to develop WRMSDs and their postures were needed to be corrected. ${ }^{12}$ Kanaparthy et al. have shown that $89 \%$ of the dental students of Jizan University, Saudi Arabia, had poor to medium levels of postural awareness during clinical work. ${ }^{13}$ Similarly, a questionnaire-based survey of 125 dental students from various dental colleges in Riyadh, Saudi Arabia, showed 53\% of students had knowledge of dental ergonomics. ${ }^{14}$ Moreover, only 39\% of dental students of Tanta University, Egypt, were aware of dental ergonomics. ${ }^{15}$ In addition, only $35 \%$ of dental students of School of Dentistry, Aracatuba, Brazil, were following ergonomics principles during clinical work. ${ }^{1}$ Similar results were shown in the dental students of MGM dental college, Mumbai, India, where $81 \%$ of the students did not know dental ergonomics. ${ }^{16}$

With respect to gender, for the question related to attending a lecture or course about dental ergonomics, males and females gave similar replies. However, regarding the questions related to knowledge about dental ergonomics, knowledge about prevention and treatment of WRMSDs, the female dental students had better understanding than the males. Our results are in line with a previous study by Kritika et al., ${ }^{17}$ while other previous studies showed no gender differences were found in the aspect of knowledge about dental ergonomics. ${ }^{11,15}$ However, it is well documented that female dental professionals are more prone to develop WRMSDs, ${ }^{5}$ particularly involving shoulder regions. ${ }^{18,19}$ Kritika et al. have postulated that the reason for female dentists to possess better dental ergonomics knowledge than males, might be because they are more prone to have WRMSDs than males, so they get more interest to learn about dental ergonomics. ${ }^{17}$

A number of studies have shown that physical strain endured by dental professionals during dispensing the dental treatment can lead to the WRMSDs. ${ }^{20-22}$ Risk of development of WRMSDs is higher among dental professionals as they have to work in a restricted environment that puts a high demand on vision, use of excessive force, and undertake precise repetitive hand and wrist movements while sitting in a static or awkward posture. ${ }^{23,24}$ Back pain has been reported to be the most common WRMSDs among dentists, followed by neck pain, high tension in upper limb muscles, carpal tunnel syndrome, tendinitis, arthrosis, etc. ${ }^{25,26}$ In spite of rising practice of fourhanded dentistry and use of ergonomically designed equipment, literature reports that at least $73 \%$ of the dentists reported suffering back and neck pain while $81 \%$ of dental professionals reported developing neck, shoulder, and arm pain. ${ }^{27,28}$

The symptoms of WRMSDs can appear very early in the dental professional's careers, and even as early as during educational training. ${ }^{29}$ Usually, such pains and soreness are slow to appear and ignored until they become chronic and permanent in nature and difficult to treat. ${ }^{30,31}$ Numerous previous studies have shown that implementation of principles of dental ergonomics have shown to minimize or eliminate WRMSDs related symptoms among dentists, ${ }^{32}$ thus on the basis of the logic of common wisdom, 'prevention is better than cure', there should be more focus to teach principles of dental ergonomics to dental students before they start their hands-on clinical training. In addition, dental students are strongly required to learn the basics of biomechanics and physiology related to WRMDs to prevent the incidence of WRMDs. Thus, the remedies for the WRMDs also rely on observing the principles of dental ergonomics and biomechanics. In addition, conditioning the muscles by regular specific exercises and stretches to withstand the workload during clinical dental work is also recommended. ${ }^{9}$ In fact, information about dental ergonomics and WRMDs is the only knowledge that is directly related to the wellbeing of dental students or dental professionals themselves, whereas all other subjects are learned to treat patients. 
A self-reported questionnaire was used in this study, which allows the possibility of over or underestimation of own experiences. Given the nature of the topic, this study should be repeated on a wider sample with consideration of confounding factors like gender age, age, and work experience.

\section{CONCLUSION}

The results of this study reveal that in general, the basic knowledge of the dental ergonomics among dental students at King Saud University, Riyadh, Kingdom of Saudi Arabia is not adequate. Since numerous previous studies have shown that the insufficient adherence to the principles of dental ergonomics can lead to WRMSDs among dental professionals, there should be a focused approach to teach the principles of dental ergonomics among dental students before they start their clinical activities.

\section{CLINICAL SIGNIFICANCE}

The students should be motivated to follow and apply the learned principles of dental ergonomics. For this, dedicated theoretical and practical courses covering all aspects of dental ergonomics should be introduced in the undergraduate curriculum. Moreover, the clinical instructors should make sure that the students correctly follow the learned principles of dental ergonomics during their clinical assignments and it is recommended to have the application of dental ergonomics principles as a part of the students' clinical evaluations. Thus, any discrepancies in following the principles of dental ergonomics should be rectified in time. This early emphasis to follow the principles of dental ergonomics correctly in the clinic can help the students to adhere to the principles of dental ergonomics throughout their future clinical working years to prevent risks leading to the WRMDs.

\section{ACKNOWLEDGMENT}

Authors would like to thank the College of Dentistry Research Center and Deanship of Scientific Research at King Saud University, Kingdom of Saudi Arabia for supporting this research project.

\section{REFERENCES}

1. Garbin AÍ, Garbin CAS, Diniz D, etal. Dental students' knowledge of ergonomic postural requirements and their application during clinical care. Eur J Dent Educ 2011;15(1):31-35.

2. YamalikN. Musculoskeletal disorders (MSDs) and dental practice Part 2. Risk factors for dentistry, magnitude of the problem, prevention, and dental ergonomics. Int Dent J 2007;57(1):45-54.

3. Finsen L, Christensen H, Bakke M. Musculoskeletal disorders among dentists and variation in dental work. Appl Ergon 1998;29(2):119-125.
4. De Sio S, Traversini V, Rinaldo F, et al. Ergonomic risk and preventive measures of musculoskeletal disorders in the dentistry environment: an umbrella review. Peer J 2018;6: e4154.

5. Alghadir A, Zafar H, Iqbal ZA. Work-related musculoskeletal disorders among dental professionals in Saudi Arabia. J Phy Ther Sci 2015;27(4):1107-1112.

6. Milerad E, Ericson MO, Nisell R, et al. An electromyographic study of dental work. Ergonomics. 1991;34(7):953-962.

7. Åkesson I, Hansson G-Å, Balogh I, et al. Quantifying work load in neck, shoulders and wrists in female dentists. Int Arch of Occup Env Health 1997;69(6):461-474.

8. Burke F, Main J, Freeman R. The practice of dentistry: an assessment of reasons for premature retirement. British Den J 1997;182(7):250.

9. Valachi B, Valachi K. Preventing musculoskeletal disorders in clinical dentistry: strategies to address the mechanisms leading to musculoskeletal disorders. J Am Dent Asso 2003; 134(12):1604-1612.

10. Bozkurt S, Demirsoy N, Günendi Z. Risk factors associated with work-related musculoskeletal disorders in dentistry. Clin Invest Med 2016;39(6):192-196.

11. Cervera-Espert J, Pascual-Moscardó A, Camps-Alemany I. Wrong postural hygiene and ergonomics in dental students of the University of Valencia (Spain)(part I). Euro J Dent Edu 2018;22(1):e48-e56.

12. Movahhed T, Dehghani M, Arghami S, et al. Do dental students have a neutral working posture? J Back Musculoskel Rehabil 2016;29(4):859-864.

13. Kanaparthy A, Kanaparthy R, Boreak N. Postural awareness among dental students in Jizan, Saudi Arabia. J Int Soc Prev Community Dent 2015;5(Suppl 2):S107.

14. Alyahya F, Algarzaie K, Alsubeh Y, et al. Awareness of ergonomics \& work-related musculoskeletal disorders among dental professionals and students in Riyadh, Saudi Arabia. J Phy Therapy Sci 2018;30(6):770-776.

15. El-sallamy RM, Atlam SA, Kabbash I, et al. Knowledge, attitude, and practice towards ergonomics among undergraduates of Faculty of Dentistry, Tanta University, Egypt. Environ Sci Pollut Res 2018;25(31):30793-801.

16. Madaan V, Chaudhari A. Prevalence and risk factor associated with musculoskeletal pain among students of MGM Dental College: a cross-sectional survey. J Contemp Dent 2012;2(2):22-27.

17. Kritika V, Laveena P, Kritika R, et al. Knowledge, attitude and behavior towards "ERGONOMICS" among oral health professionals in jodhpur city, Rajasthan, India. IJ Pre Clin Dent Res. 2014;1(3):5-9.

18. Chowanadisai S, Kukiattrakoon B, Yapong B, et al. Occupational health problems of dentists in southern Thailand. Int Dent J 2000;50(1):36-40.

19. Al-Mohrej OA, AlShaalan NS, Al-Bani WM, et al. Prevalence of musculoskeletal pain of the neck, upper extremities and lower back among dental practitioners working in Riyadh, Saudi Arabia: a cross-sectional study. BMJ open 2016;6(6):e011100.

21. Kalghatgi S, Prasad KVV, Chhabra KG, et al. Insights into Ergonomics Among Dental Professionals of a Dental Institute and Private Practitioners in Hubli-Dharwad Twin Cities, India. Safety and health at work 2014;5(4):181-185.

22. Graham C. Ergonomics in dentistry, Part 1. Dentistry today 2002;21(4):98. 
23. Association AD. An Introduction to Ergonomics: Risk Factors, MSDs, Approaches and Interventions. A Report of the Ergonomics and Disability Support Advisory Committee. Council on Dental Practice 2004. 2006.

24. Khan SA, Chew KY. Effect of working characteristics and taught ergonomics on the prevalence of Musculoskelet Disord amongst dental students. BMC Musculoskelet Disord 2013;14(1):118.

25. Yousef MK, Al-Zain AO. Posture evaluation of dental students. JKAU Med Sci 2009;16(2):51-68.

26. Alghadir A, Zafar H, Iqbal ZA. Work-related musculoskeletal disorders among dental professionals in Saudi Arabia. J Phys Ther Sci. 2015;27(4):1107-12. Epub 2015/05/23.

27. Pargali N, Jowkar N. Prevalence of musculoskeletal pain among dentists in Shiraz, Southern Iran. Int J Occup Environ Med 2010;1(2 April).
28. Hayes M, Cockrell D, Smith D. A systematic review of musculoskeletal disorders among dental professionals. Int J Dent Hyg 2009;7(3):159-165.

29. Gupta A, Ankola AV, Hebbal M. Dental ergonomics to combat musculoskeletal disorders: a review. Int J Occup Saf Ergon 2013;19(4):561-571.

30. Diaz-Caballero A-J, Gómez-Palencia I-P, Díaz-Cárdenas S. Ergonomic factors that cause the presence of pain muscle in students of dentistry. Medicina oral, patologia oral y cirugia bucal 2010;15(6):e906.

31. Lindfors P, Von Thiele U, Lundberg U. Work characteristics and upper extremity disorders in female dental health workers. J Occup Health 2006;48(3):192-197.

32. Droeze EH, Jonsson H. Evaluation of ergonomic interventions to reduce musculoskeletal disorders of dentists in the Netherlands. Work 2005;25(3):211-220. 